\section{Spleen rupture complicating upper endoscopy}

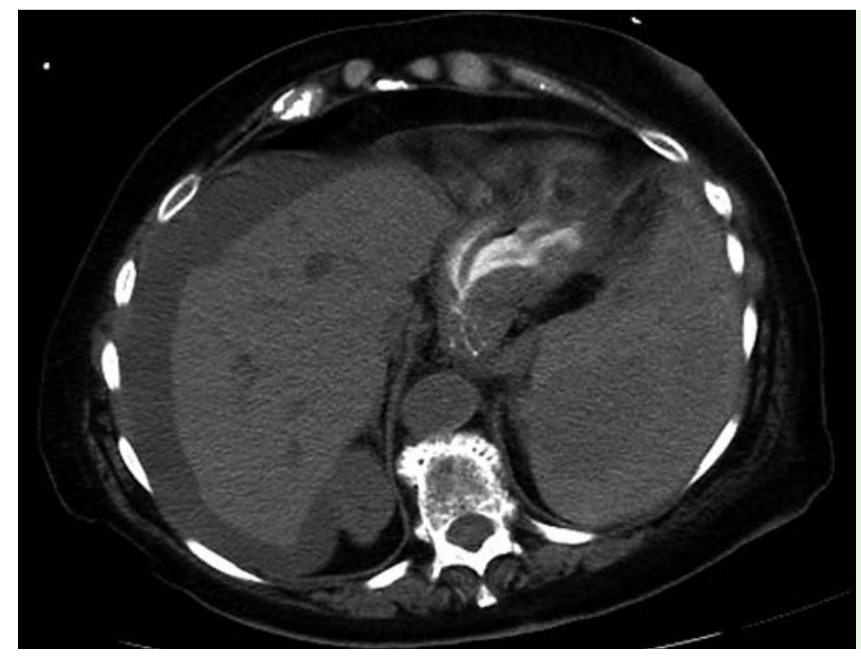

Fig. 1 Computed tomography (CT) scan of abdomen in an 81year-old woman with generalized weakness, persistent nausea, and difficulty swallowing, showing hemoperitoneum, subcapsular spleen hematoma, and blood around the liver.

An 81-year-old woman with history of chronic lymphocytic leukemia and recent diagnosis of Clostridium difficile colitis, and maintained on oral vancomycin, presented for generalized weakness, persistent nausea, and a long history of difficulty swallowing (food hangs in her chest and does not move down to her stomach). Workup revealed low potassium and white blood cell count of $41000 / \mathrm{mm}$ with lymphocytes predominance. Renal function and liver enzyme levels were within normal. The patient received intravenous fluids and electrolytes replacement. A diagnostic upper endoscopy was done to delineate the cause of the dysphagia, and the findings were tortuous esophagus, slight narrowing of the esophageal sphincter, and an enormous intrathoracic stomach. Most of the stomach except for the antrum was above the diaphragm. The scope was passed through the hiatus entering the antrum. Below the hiatus, there was acute angulation into the antrum and fair maneuverings were required to reach the pylorus and into the duodenum. Biopsies were taken and esophageal sphincter balloon dilatation was done. Shortly after the procedure, the patient became diaphoretic, hypotensive, and tachycardic, requiring fluid resuscitation and vasopressors. She also developed abdominal pain and marked tenderness, predominantly at the right upper quadrant.

A blood workup revealed slight drop in hemoglobin but increase in the white blood cell count up to $70000 / \mathrm{mm}$. An immediate computed tomography (CT) scan without contrast showed massive hemo- peritoneum with subcapsular hematoma on the spleen ( $\bullet$ Fig. 1 ). The patient was diagnosed as having splenic rupture. Exploratory laparotomy showed large hemoperitoneum (about $1500 \mathrm{~mL}$ blood), subcapsular hematoma of the lateral inferior portion of the spleen, as well as a large amount of coagulated blood in the splenic fossa and free blood in the peritoneal cavity. The spleen short gastric vessels attached to the stomach fundus were intact, but partial disruption of the lateral peritoneal attachments of the spleen was noted. Splenectomy was done and the bleeding sites were sutured. The stomach was found to be herniated through a large paraesophgeal hernia. The stomach was then fixed with double gastrostomy tube gastropexy. A pathological study of the spleen showed normal parenchyma. The patient recovered well and was discharged several days later.

Rupture of the spleen following trauma is well known. Spontaneous rupture of the spleen has also been described in various conditions such as certain hematological malignancies, infections (malaria, Epstein-Barr virus infection, human immunodeficiency virus infection), metabolic disorders, tumors of the spleen, pregnancy, and connective tissue diseases [1,2]. It is also described as a complication after colonoscopy, left-sided thoracotomy, and shockwave lithotripsy [1,2]. Some serious complications such as viscus perforation and gastrointestinal bleeding have been rarely reported after upper endoscopy [3]. However, spleen injury or rupture is an exceptional and very rare complication following gastroscopy [3]. To our knowledge, only few cases have been reported in the medical literature [3-5].

We think that the excessive stretching of spleno-diaphragmatic ligaments and of spleno-peritoneal lateral attachments during endoscopy and possibly the location of most of the stomach in the thoracic cavity had contributed to the spleen rupture $[5,6]$. Rapid diagnosis in the presence of suggestive symptoms of hemodynamic instability and abdominal pain following upper endoscopy is life-saving.

\section{Endoscopy_UCTN_Code_CPL_1AH_2AJ}

\section{Competing interests: None}

\section{F. Jabr ${ }^{1}$, N. Skeik ${ }^{2}$}

${ }^{1}$ Hospital Medicine, Horizon Medical Center, Tennessee, USA

${ }^{2}$ Vascular Medicine, Abott Northwestern Hospital, Minneapolis, USA

\section{References}

1 Lopez-Tomassetti Fernandez EM, Delgado Plasencia L, Arteaga González IJ et al. Atraumatic rupture of the spleen: experience of 10 cases. Gastoenterol Hepatol 2007; 30: 585-591

2 Rhee SJ, Sheena Y, Imber C. spontaneous rupture of the spleen: a rare but important differential of an acute abdomen. Am J Emerg Med 2008; 26: 733, E5-E6

3 Hunter RC Jr. Gastroscopy and delayed rupture of the spleen; a review and report of possible case. Gastroenterology 1955; 29 : 898-906

4 Lewis FM, Moloo N, Stiegmann GV et al. Splenic injury complicating therapeutic upper endoscopy and ERCP. Gastrointest Endosc 1991; 37: 632-633

5 Estevez-Boullosa P, Alonso-Aguirre PA, CoutoWörner I et al. Splenic rupture following a diagnostic upper endoscopy. World J Gastrointest Endosc 2010; 2: 235-236

6 Lemon $M$, Dorsch $M$, Street $K$ et al. Splenic rupture after vomiting. J R Soc Med 2001; 94: $527-528$

\section{Bibliography}

Dol http://dx.doi.org/

10.1055/s-0032-1308924

Endoscopy 2012; 44: E206

(c) Georg Thieme Verlag KG

Stuttgart · New York

ISSN 0013-726X

\section{Corresponding author}

\section{F. Jabr}

Horizon Medical Center - Hospital Medicine HWY 70 E, Dickson

Tennessee 37055

USA

fijabr@gmail.com 